\title{
What we've learned in 2008
}

\author{
Amanda Leigh Mascarelli looks at how far our understanding of climate change has come in \\ the past twelve months.
}

\begin{abstract}
1. Other greenhouse gases are also worrying Scientists have long been aware of greenhouse gases other than carbon dioxide, but $\mathrm{CO}_{2}$ has received most of the scientific and public attention owing to its prevalence in fossil fuel emissions and its long atmospheric life. However, scientific research published this year suggests that other heat-trapping gases also provide
\end{abstract} cause for concern. In July, scientists led by Michael Prather at the University of California, first proposed that nitrogen trifluoride, a gas produced in the manufacture of gadgets such as MP3 players and flat screen TVs, was likely to become a much greater contributor to climate change than previously assumed, mainly because of the growing demand for such products (Geophys. Res. Lett. 35, L12810; 2008). Their hypothesis was confirmed in October when Ray Weiss at the Scripps Institution of Oceanography, California, and colleagues found that the atmospheric concentration of the gas has increased 20-fold over the past three decades (Geophys. Res. Lett. 35, L20821; 2008). Also this year, several independent research groups reported a surge in emissions of methane (Geophys. Res. Lett. 35, L22805; 2008 and Nature 456, 628-630; 2008), a greenhouse gas twenty times more potent than $\mathrm{CO}_{2}$. The exact source of the methane emissions remains a mystery.

\section{Arctic summer sea ice is in rapid decline Arctic sea ice saw some recovery this summer, compared with the record- breaking low set in 2007 . However, the 2008 summertime minimum was still the}

second lowest level recorded since 1979, when the first satellite data of sea ice became available (National Snow and Ice Data Center 16 September 2008; http://nsidc. com/arcticseaicenews/2008/091608.html). In 2007, the Intergovernmental Panel on Climate Change (IPCC) projected that at the current level of emissions, summer sea ice could vanish completely anytime from

only shrinking but is decreasing in overall volume (Geophys. Res. Lett. 35, L22502; 2008). This is worrying because thin ice is more vulnerable to melting and creates a feedback effect: as the ice melts, dark open water soaks up more of the sun's rays and further accelerates melting. Loss of Arctic summer sea ice could have not only regional, but global, effects and is widely regarded as a potential 'tipping element', in which a 'kick' to the system, driven even by natural variability, could lead to rapid, runaway warming.

\section{Warming is already having an impact}

The effect of human-induced warming on biological and physical systems, such as patterns of species migration and seasonal shifts, came into clear focus this year. An international team of researchers conducted a sweeping analysis of nearly 30,000 biological species and physical phenomena, such as timing of pollen release and bird nesting, and trends in ice melting. For the first time, researchers attributed pronounced worldwide changes in these systems to human-caused climate change (Nature 453, 353-357; 2008). Spurred on

by concerns that species and ecosystems may not survive such shifts, conservationists began to talk seriously about relocating species to help them adapt (Science 321, 345-346; 2008).

And threatened by the loss of its icy habitat, the polar bear became the first species to be listed as climate-

2040 to beyond 2100. But the extensive losses during the past two summers have led scientists to speculate that the Arctic Ocean may be ice-free in the summertime much sooner than anticipated. In October, scientists reported that the thickness of winter sea ice plummeted after the 2007 minimum, showing that the ice pack is not threatened under the Endangered Species Act, following a protracted legal battle by environmentalists.

\section{The hockey stick holds up}

A follow-up to the infamous 1998 'hockey stick' curve confirmed that the past two decades are the warmest in recent 
history. Climatologist Michael Mann's contentious graph has become a symbol of the fierce debates on evidence for global warming, to the extent that an independent investigation into the study was performed at the request of US Congressman Joe Barton. The 2006 report that resulted from the Barton enquiry criticized Mann and colleagues for their reliance on tree-ring data from bristlecone pines as a proxy to reconstruct Northern Hemisphere temperatures over the past 1,000 years. Although their earlier work had been largely vindicated, in September the same team revised their global surface temperature estimates for the past 2,000 years, using a greatly expanded set of proxies, including marine sediments, ice cores, coral and historical documents (Proc. Natl Acad. Sci. USA 105, 13252-13257; 2008). The team reconstructed global temperatures with and without inclusion of the tree-ring records: without their inclusion, the data showed that recent warming is greater than at any point in at least the past 1,300 years; inclusion of treering data extended this period to at least 1,700 years. According to the Christian Science Monitor: "It still looks a lot like the much-battered, but still rink-ready stick of 1998. Today the handle reaches further back and it's a bit more gnarly. But the blade at the business end tells the same story."

\section{Sceptics are still out there}

Despite a near-universal scientific consensus to the contrary, climate change sceptics continued this year to insist that global warming is a farce. Although the Republican party officially acknowledges the role of humans in climate change, Alaskan Governor Sarah Palin remained unconvinced during her campaign as Senator John McCain's vice presidential running-mate, asserting "I'm not one though who would attribute [global warming] to being manmade". The NBC late night show Saturday Night Live famously satirized Palin: when asked about her views on global warming, Palin's double Tina Fey responded, "I believe it's just God hugging us closer." More recently, climate bloggers have been up in arms over two articles published by the website Politico. One calls into question the science behind global warming and the other suggests that extreme cold-weather events coincide with appearances by former US vice president Al Gore. Little wonder that American public opinion still fluctuates over whether climate change is a serious problem (Wired Science 14 May 2008; http://blog. wired.com/wiredscience/2008/05/theclimate-cha.html).

\section{AND WHAT WE'RE STILL WORKING ON}

1. How much warming and by when Although there is wide agreement that we will see a warming trend in atmospheric and sea surface temperatures over the next century, just how climate will change in the short term is less certain. One of the first studies to address this concluded that warming may slow for a decade before rapid climate change takes off(Nature 453, 84-88; 2008). Noel Keenlyside of Germany, and colleagues found that owing to changes in ocean circulation that occur on decadal time scales, global average surface temperatures in parts of the ocean may not increase over the period from 2005 to 2015 , compared with 2000 to 2010 , and that some surface waters could even cool slightly. Their findings do not imply the Leibniz Institute of Marine Sciences,

that global warming is not happening, but instead that natural oscillations in the climate system could lead to short-term changes that temporarily eclipse humaninduced warming. However, unconvinced by the temperature forecasts of Keenlyside et al. a group of esteemed climate scientists on the Real Climate blog staked $€ 5,000$ against the prediction that falling temperatures in some regions will cause a slight slow down in global warming. We'll have to wait until 2015 to know for sure.

\section{Where to stabilize}

A muddy point that perhaps only became muddier in 2008 is the concentration at which we must stabilize atmospheric greenhouse gases to avert a dangerous degree of change. Atmospheric $\mathrm{CO}_{2}$ concentrations today hover around 385 parts per million (p.p.m.), and many

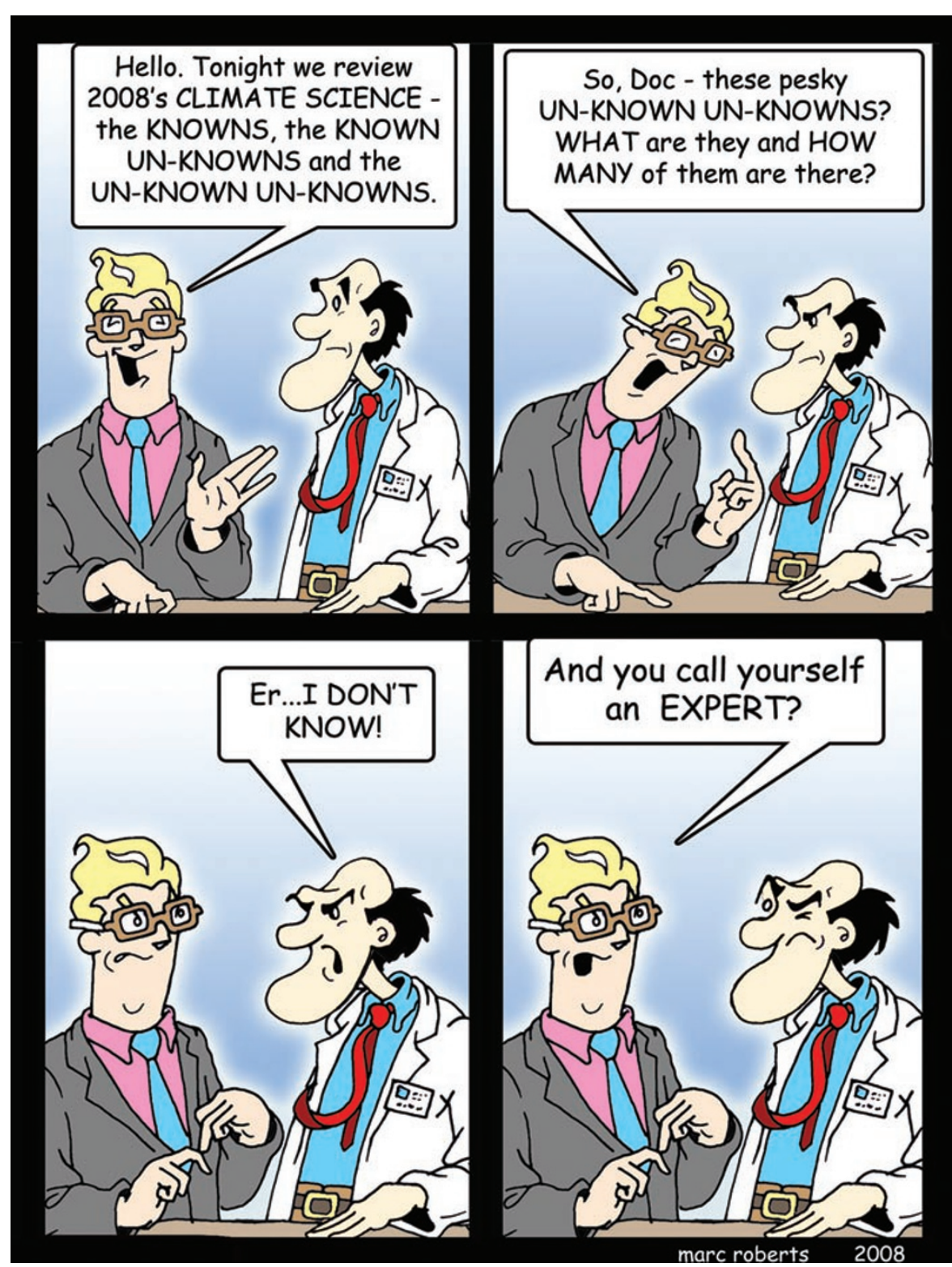


scientists have settled on 400 to 450 p.p.m. as the upper limit to keep warming below $2{ }^{\circ} \mathrm{C}$ above pre-industrial levels. But NASA climatologist James Hansen is one of a group of scientists now saying that more stringent limits of approximately 350 p.p.m. will be necessary to avoid "irreversible catastrophic effects" (J. Hansen et al. Columbia University 2008; www.columbia. edu/ jeh1/2008/TargetCO2_20080407. pdf). Others are veering in the opposite direction: in a report for the Australian government this year, economist Ross Garnaut reiterated Professor Nick Stern's 2006 recommendation to stabilize the atmospheric concentration of $\mathrm{CO}_{2}$ at up to 550 p.p.m. (R. Garnaut, The Garnaut Climate Change Review; Cambridge University, 2008; www.garnautreview.org. $\mathrm{au} /$ index.htm). There may be remaining scientific uncertainty about just how much $\mathrm{CO}_{2}$ is too much, to avoid disaster, but if the current state of play is anything to go by, reaching a final figure in any agreement will also be a question of what is politically achievable.

\section{Where the missing carbon is going} Surprising as it sounds, scientists still do not have a clear grasp of where carbon is coming from, where it's going and in what amounts. Yet, under the Kyoto Protocol, developed nations that have ratified the agreement are to receive credits for sequestering carbon through improved land management practices and reforestation. About half of the $\mathrm{CO}_{2}$ that wafts into the atmosphere from fossil fuel combustion is absorbed by the oceans, plants, forests and croplands, but how much of the carbon is swallowed up by the oceans versus land is still unclear (Global Change Biol. 14, 2910-2922; 2008, Nature Geosci. 1, 569-570; 2008 and Eos Trans. AGU 89, doi:10.1029/2008EO430001; 2008). One reason for the dearth of information is that ground-based monitoring stations are few and far between, and until now, the technology hasn't been available to obtain fine-scaled, precise measurements of $\mathrm{CO}_{2}$ in the atmosphere. But the launch next year of two carbon-detecting satellites, NASA's Orbiting Carbon Observatory and the Japanese Greenhouse Gases Observing Satellite, should soon help to fill in this knowledge gap, which is critical to establishing a reliable carbon accounting system.

\section{Whether warming worsens storms}

The jury is still out on whether hurricanes will increase in intensity, frequency or duration as a result of global warming. Globally, the number of major hurricanes has shot up by 75 per cent since 1970 , but the role of human activity in this rise has remained contentious. This year, new evidence has caused leading experts to reassess their positions on this key issue. Weighing in on the debate early on, Kerry Emanuel of the Massachusetts Institute of Technology used a bespoke model to show that warming should reduce the frequency of hurricanes globally, although hurricane intensity may increase in some locations (Bull. Am. Meteorol. Soc. 89, 347-367; 2008). Supporting these predictions was a paper in May (Nature Geosci. 1, 359-364; 2008) that projected fewer Atlantic hurricanes during the twenty-first century. In September, James Elsner of Florida State University and colleagues concluded that in the Atlantic, the strongest tropical cyclones will grow even stronger in a warming world (Nature $455,92-95 ; 2008)$. One explanation for the smattering of results is that scientists do not yet have a clear understanding of the relationship between sea surface temperature and hurricane formation on local or global scales. A team of researchers led by Gabriel Vecchi of the US National Oceanic and Atmospheric Administration recently summarized the difficulties in predicting hurricane activity (Science 322, 687-689; 2008). Ultimately, they argue that relative, rather than absolute, warming of regions such as the Atlantic Ocean is probably behind the recent surge in hurricane activity. And predictions show that relative warming will remain fairly constant throughout the remainder of this century. If their hypothesis is right, the worst hurricane seasons may already be behind us.
5. How fast Greenland is melting One of the greatest wild cards in predicting how the climate system will respond to warming is the Greenland Ice Sheet. Complete melting of Greenland could raise sea level by seven metres and spell catastrophe for coastal cities and millions of inhabitants. Scientists previously assumed that this melting would happen gradually over 1,000 years or more. However, this is being re-examined in light of new evidence, including a study showing that Greenland could experience rapid melting over centuries, rather than millennia, and that sea level could rise by 1.3 metres by 2100 as a result (Nature Geosci. 1, 620-624; 2008). A recent study reported in Science looked closely at the possibility of large sea level rise by 2100 and concluded that sea level could rise by a maximum of two metres by 2100 if all variables were accelerated and pushed to the extreme, but that sea level rise of 0.8 metres by 2100 is a more likely outcome (Science 321, 1340-1343; 2008). Scientists know that the Greenland Ice Sheet is undergoing dramatic melting, but accurately capturing its status in climate models and predicting future behaviour in response to warming is difficult due to a lack of long-term observations and data. In addition, scientists don't yet have a handle on ice sheet dynamics, including how subsurface melting contributes to slipping and sliding of the ice sheet. Two studies this year shed light on how meltwater may lubricate the bottom of the ice sheet, contributing to its slippage towards the ocean (Science 320, 778-781; 2008 and Science 320, 781-783; 2008). But by far the most disturbing question that remains is whether Greenland has already endured enough warming to push it to the point of no return.

Published online: 18 December 2008

doi:10.1038/climate.2008.142

Amanda Leigh Mascarelli is a freelance science writer based in Denver, Colorado. 